\title{
ICE FLOW VELOCITY MAPPING OF EAST ANTARCTICA FROM 1963 TO 1989
}

 \\ ${ }^{a}$ Center for Spatial Information Science and Sustainable Development, Tongji University, 1239 Siping Road, Shanghai, China - \\ (chengyuan_1994, qiaogang, tianyixiang, xhtong, rli)@tongji.edu.cn, yewenkai1990@gmail.com, (943066287, \\ 794277895)@qq.com, liyj951005@163.com,15589997263@126.com \\ ${ }^{\mathrm{b}}$ College of Surveying and Geo-Informatics, Tongji University, 1239 Siping Road, Shanghai, China
}

Commission III, CHGCS III/9

KEY WORDS: Ice Velocity, East Antarctica, Landsat images, DISP, Mapping

\begin{abstract}
:
Long-time serial observation of surface ice flow velocity in Antarctic is a crucial component in estimating the mass balance of Antarctic ice sheet. However, there is a lack of historical continental scale velocity maps of Antarctica before the 1990s. Historical optical images such as ARGON and Landsat images before 1990s are difficult to be used for ice flow velocity mapping, due to the fact that they are mostly not strictly geo-processed (e.g., ortho-rectified) and the image quality is lower than those of recent sensors. This paper presents a systematic framework for developing a surface velocity map of East Antarctica from 1963 to 1989 based on historical ARGON and Landsat images, followed by analysis of spatial-temporal changes of the ice flow velocity in some major glaciers, as well as the dynamic changes. The preliminary comparison with existing products suggests that the glaciers in Wilkes Land experienced an increasing trend with obvious fluctuations during the past $\sim 50$ years, while the glaciers near Transantarctic Mountains tended to be stable or slightly fluctuating to a certain degree.
\end{abstract}

\section{INTRODUCTION}

To better understand the mechanism of interactions between global climate and Antarctic ice sheet, long-time serial ice flow velocity should be studied. The observation of ice flow plays a significant role in revealing how the ice transports from inland areas to the grounding line and then flows into the sea. What's more is the surface ice flow velocity in Antarctic is a crucial parameter for quantitative estimating mass balance of Antarctic ice sheet by calculating the ice flux.

Much efforts have been made to acquire ice flow velocity of Antarctica. The earliest method of measuring ice velocity is to use some stakes on the ice sheet, a method that is of high accuracy but not suitable for large areas in Antarctica due to the harsh environment there (Dorrer et al., 1969; Swithinbank, 1969). Thereafter, GPS with higher accuracy and portability was utilized in field measurement of ice velocity, but this kind of observation is still limited to smaller regions (Frezzotti et al., 1998; Manson et al., 2000; Urbini et al., 2008). However, application of remote sensing data makes it possible to implement long-range, longtime and large-scale monitoring of Antarctic ice sheet, and the insitu measurement results (ground truth data) can be compared with the remote sensing results for verification. Two types of remote sensing data including optical data and SAR data are utilized to derive the ice flow velocity. The first one is optical data which can date back to 1963 (Fujii, 1981), which provide large-scale observations based on optical images before Landsat images. In this method, tie points are selected manually between two images taken at different time to calculate ice flow velocity (Lucchitta et al., 1986; Li et al., 2016). Then feature tracking between two optical images is adapted to measure ice flow velocity in Antarctica based on normalization cross-correlation algorithm (Scambos et al. 1992). This method was improved by employing Fourier transform in frequency domain or matching directly based on phase (Reddy et al., 1996). The efficiency of extracting ice displacements from optical images has been enhanced with the improvement of image matching algorithms, and optical images obtained from Landsat satellites launched after 1972 (especially Landsat 7 and Landsat 8) were employed in many studies (Scambos et al., 1992; Whillans et al., 1995; Leprince et al., 2007; Gardner et al., 2017; Shen et al., 2018). Declassified Intelligence Satellite Photographs (DISP) including CORONA, ARGON and LANYARD was declassified and used to extract the ice velocity of Larsen B ice shelf, and a parallax decomposition method was utilized to generate the ice flow velocity and DTM at same time from ARGON images in Rayner glacier, giving us an understanding about the ice flow pattern before 1970s (Ruffer, 1995, Liu et al., 2012; Li et al., 2017a; Li et al., 2017b, Ye et al. 2017). Furthermore, ice flow velocity maps covering the entire Antarctica were realized by using Landsat 8 images from 2014 to 2015 (Gardner et al., 2017; Shen et al., 2018).

The second remote sensing data source is SAR data, which is of high accuracy and can be used regardless of the cloud and weather condition. Interferometric Synthetic Aperture Radar (InSAR) technology was applied to extract ice flow velocity by its interference coherence characteristics. D-InSAR technology was also used to detect the velocity in Rutford glacier based on two SAR images with time interval of several days (Goldstein et al., 1993). After that, the first ice flow velocity map of the entire Antarctica was derived based on SAR data acquired during 1996 and 2009 (Rignot et al., 2011). This ice flow velocity map set (MEaSUREs) has been updated by Mouginot et al, and annual velocity d maps were provided based on SAR data like Sentinel1 and RADARSAT-2 (Mouginot et al., 2017).

Most existing ice flow maps were generated after 1990s, leading to our limited understanding of the ice flow evolution over long time series. To identify the influence of climate change on Antarctic ice sheet, long-term observations on the flow velocity are necessary. Therefore, this paper presents compiling

\footnotetext{
* Corresponding author
} 
techniques for East Antarctic ice velocity mapping based on historical optical imagery from 1960s to 1980s and compares the results with those of existing products.

\section{METHODS}

A complete framework including selecting appropriate image pairs, matching the corresponding points, eliminating the mismatches and mapping the results is proposed in this study (see Figure 1).

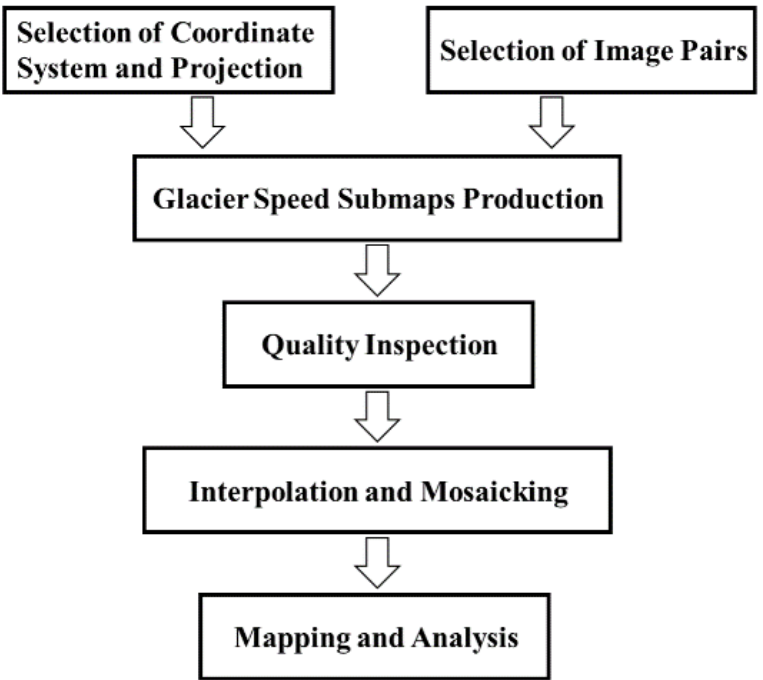

Figure 1. Framework of ice flow velocity mapping based on historical optical images

\subsection{Historical optical imagery used to extract ice flow velocity}

We used optical images of ARGON (KH-5 satellites) which was operated from February 1961 until August 1964 to extract ice flow velocity in the Antarctic Ice Sheet (Bindschadler et al., 1998). Each image is about 5 inch in size and covers an area of about $540 \mathrm{~km} \times 540 \mathrm{~km}$. Figure 2 shows the coverage of KH-5 9058A and 9059A of ARGON images.

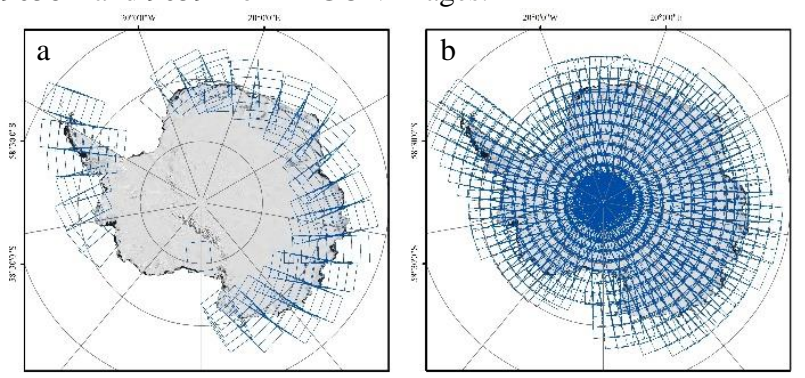

Figure 2. Coverage of ARGON images, 9058A (a) and 9059A (b)

Kim et al. (2007) used a range of techniques including orthorectification and mosaicking to assemble ARGON images into a map mosaic covering the regions from the coastline to the interior around of the Antarctic continent. The geometric accuracy is approximately equal to the ground resolution of ARGON image which is about $140 \mathrm{~m}$. In this paper, this product is used for ice flow velocity mapping in some areas.

We also used Landsat MSS and TM images in the 70s and 80s to obtain ice motion information. Each Landsat MSS and TM image has a spatial resolution of $60 \mathrm{~m}$ and $30 \mathrm{~m}$ respectively. All Landsat data downloaded and used in this paper are provided by
USGS. The coverage of Landsat images in the 70 s and 80 s can be seen in Figure 3.


Figure 3. Coverage of Landsat images in the 70s (a) and 80s (b)

\subsection{Matching methods}

2.2.1 Selection of Image Pairs: The measurement of ice displacement involves different texture features on the surface of ice sheet, so we generally selected the images with little or even no cloud coverage to produce the velocity map. In addition, to better match two images and track ice mass displacements, the time interval between the two images should also be taken into account. It is optimal to control ice displacements in the images within 5-15 pixels ( $\mathrm{Li}$ et al., 2018). For example, given the resolution of $60 \mathrm{~m}$, for areas with fast ice flow (such as more than $600 \mathrm{~m} \mathrm{yr}^{-1}$ ), image pairs with a time interval of around 1 year would be suitable. For areas with slower ice flow velocity, a longer interval may be needed.

2.2.2 Matching methods: Before matching, Adaptive Histogram Equalization, Median Filter, Wallis Adaptive Filter, etc. are selectively used to de-noise and enhance the images to improve the probability of matching success, and all of the images have been ortho-rectified to meet the requirement that the calibration errors are within one pixel. Then two matching methods are adopted to cope with different image pairs, e.g., feature \& grid-based image matching with constraints for Landsat image pairs or ARGON and Landsat image pairs, and the parallax decomposition method for ARGON image pairs in epipolar image space (Li et al., 2017b; Ye et al., 2017).

\subsection{Estimation of the uncertainties}

The uncertainties of ice flow velocity stem from the calibration error of images and feature matching error between two images, and the errors are affected greatly by the resolution of images. Based on the assumption that these two errors are independent and taking time intervals into consideration, the total error can be calculated by the error propagation function.

\subsection{Ice flow velocity mapping}

After gaining numerous matching points, interpolation enables us to obtain a continuous surface of ice flow field and then produce an ice flow velocity map. Here, we chose Kriging and Natural Neighbour algorithms to complete interpolation. Kriging interpolation features a solid theoretical basis and it can help to obtain the pattern of ice flow velocity with relatively small prediction errors (Oliver et al., 1990), despite the fact that this method sometimes is time-consuming because of high total number of input points and the function involved needs to be selected based on experience. Nature Neighbour interpolation is based on a simple principle that the predicted value is affected by the closet subsets of existing points, and this method is suitable and time-effective when there are numerous input points (Childs, 
2004). For different areas with different points amount and ice flow velocity pattern, we chose the more suitable interpolation methods according their characteristics to interpolate.

The final step of the process is to mosaic the results from different data sources, which involve various sensors, resolutions and time periods. Generally, image pairs with similar time intervals were used to complete the mapping for adjacent regions with certain ice flow velocity. Ice flow velocity maps using matching points from different data sources are required to overlap margins between areas. The individual maps can be mosaicked into the overall map only when the inconsistencies in the margins are sufficiently small to ensure a high quality of the product (Li et al., 2018)

\section{ICE FLOW MAP OF EAST ANTARCTICA FROM 1960S-1980S}

We used the optical images between 1960 and 1989 from ARGON, including the images and a mosaic (Kim, 2007), and LANDSAT images to develop ice surface velocity map for the entire East Antarctica (except for areas where the latitude is greater than 82 degrees and outside the Landsat coverage) and have finished about $85 \%$ of the entire area. In addition to these optical images, Landsat Image Mosaic of Antarctic (LIMA) and the RADARSAT Antarctic Mapping Project (RAMP) digital elevation model were also used to ortho-rectify these images.

The resolution of this velocity map is $500 \mathrm{~m}$, which was given by average point density in the whole region. This map was completed by using LANDSAT 1-5 image pairs and image pairs combined by ARGON and LANDSAT images. The time span of each image pair varies from less than 365 days to more than 10 years and the velocity on this map represents the average velocity (the unit is meters per year) during the time period.

The precision of ice flow velocity measurements varies with the sensor, geographical location, and time period of the image pair used. The main sources of errors in this velocity map are the calibration of images and the feature matching. According to the statistical results of manual inspection based on obvious surface features on the ice sheet, the accuracy of the estimated ice displacement from different data sources is shown in Table 1 where image pairs are combined using ARGON, MSS and TM LANDSAT images. The error of the estimated ice flow velocity is the total error divided by the time interval of the image pair.

\begin{tabular}{|c|c|c|c|}
\hline Type of Image pair & $\begin{array}{c}\text { Georeferencing } \\
\text { Error }\end{array}$ & $\begin{array}{c}\text { Matching } \\
\text { Error }\end{array}$ & $\begin{array}{c}\text { Total } \\
\text { Error }\end{array}$ \\
\hline ARGON \& ARGON & $\mathrm{m}$ & $\mathrm{m}$ & $\mathrm{m}$ \\
ARGON \& MSS & 124 & 51 & 136 \\
LANDSAT MSS & 42 & 41 & 58. \\
LANDSAT MSS \& TM & 33 & 40 & 52 \\
LANDSAT TM & 22 & 23 & 31 \\
\hline
\end{tabular}

Table 1. The uncertainties of different image types

The whole ice flow velocity map is consisted by submaps generated from different types of image pairs. Ice flows from the inland area to the coastal area driven by the gravity, and the velocity is relatively small in high latitude regions and around the ice divide. In this map, areas with velocity less than $50 \mathrm{~m} \mathrm{yr}^{-1}$ are about 6 million $\mathrm{km}^{2}$, which accounts for more than $85 \%$ of the East Antarctic. The ice starts to deform around the ice divides and then deformational velocity is produced, while basal slip gradually increases towards the sea and becomes an important contributor of the surface flow velocity. The ice flows through the grounding line and discharges from glacier outlets, and these areas with ice flow velocity greater than $50 \mathrm{~m} \mathrm{yr}^{-1}$ account for only $\sim 12$ percent of the entire East Antarctic.

\section{COMPARISON WITH EXISTING ICE FLOW VELOCITY PRODUCTS}

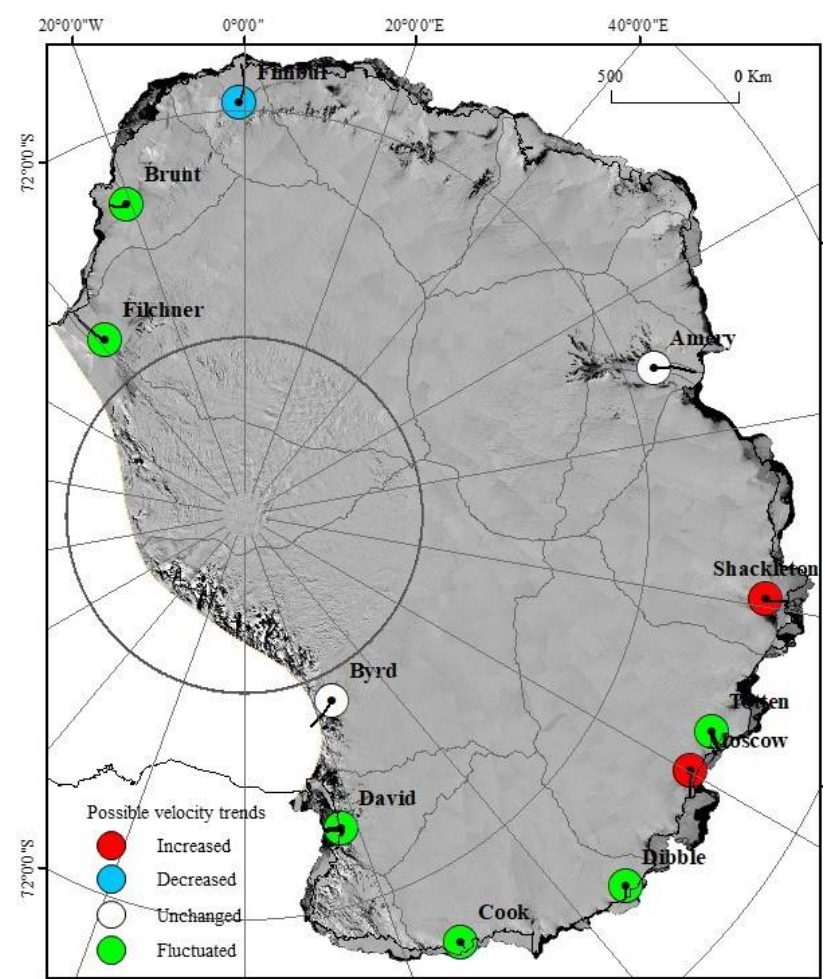

Figure 4. Potential velocity trends from 1963 to 2016, a preliminary comparison among our map (1963-1989), RAMP velocity map (1997-2000), MEaSUREs velocity map (19962009) and LISA velocity map (2015-2016) (Jezek et al., 2002; Rignot et al., 2011; Fahnestock et al., 2016); the background is a Landsat Image Mosaic of Antarctica (Bindschadler, R., et.al, 2008)

Shen et al. (2018) estimated the ice discharge of Antarctica in 2007-2009, 2014 and 2015 and found an acceleration of ice speed in Wilkes Land, East Antarctica, and Gardner et al. (2017) concluded that ice draining from the whole East Antarctica was relatively constant over the $\sim 7$ years while the mass loss of West Antarctic Ice Sheet has been increased. We profiled the abovementioned four velocity maps at major glacier outlets and analysed potential trends from 1963 to 2016 . Figure 4 shows the possible velocity trends at different glaciers with different colors, and the lines represent the position of each profile. With the speed rising or falling, the point is marked as increased (red) or decreased (blue); if the change is small and within the error range shown in Table 1, the point is set to white; if the speed fluctuates during this period, the point will be green. According to Figure 4, the obvious fluctuation occurred in the glaciers in Wilkes Land, East Antarctica, including Totten glacier, Dibble glacier and Cook glacier. These glaciers are generally small in size, and thus more vulnerable to ocean forces and climate change to a certain extent. Ice flow speeds of Shackleton Ice Shelf and Moscow glacier have increased, while Amery Ice Shelf, the third largest ice shelf in Antarctica, experienced an unchanged period. Byrd glacier and David glacier near Transantarctic Mountains showed a steady and slight fluctuating trend respectively during this time. 
In addition, there were fluctuating trends in the speeds of Filchner Ice Shelf and Brunt glacier around Weddell Sea, compared with a slight decrease in the speed of the glaciers in Queen Maud Land like Fimbul glacier.

\section{CONCLUSIONS}

In this study, a systematic framework is proposed to generate ice surface velocity maps based on historical ARGON and Landsat images, and a 1960s-1980s ice flow velocity map of the entire East Antarctic is produced (85\%) for the first time. Comparing this preliminary map with other existing products, we analysed the spatial-temporal changes of the ice flow velocity in some major glaciers and the dynamic change of Antarctic ice sheet over several decades. The preliminary comparison with existing products suggests that the speed of the glaciers in Wilkes Land experienced an obvious fluctuation or an increasing trend during 50 years, while the glaciers near Transantarctic Mountains tended to be stable or slightly fluctuating to a certain degree.

\section{ACKNOWLEDGEMENTS}

This work has been supported by the National Key Research \& Development Program of China (No. 2017YFA0603102) and the National Science Foundation of China (41730102).

\section{REFERENCES}

Bindschadler, R., \& Seider, W. (1998). Declassified intelligence satellite photography (DISP) coverage of Antarctica.

Bindschadler, R., Vornberger, P., Fleming, A., Fox, A., Mullins, J., Binnie, D., ... \& Gorodetzky, D. ,2008. The Landsat image mosaic of Antarctica. Remote Sensing of Environment, 112(12), 4214-4226.

Childs, C. (2004). Interpolating surfaces in ArcGIS spatial analyst. ArcUser, July-September, 3235, 569.

Dorrer, E., Hofmann, W., \& Seufert, W., 1969. Geodetic results of the Ross Ice Shelf Survey expeditions, 1962-63 and 1965-66. Journal of Glaciology, 8(52), pp. 67-90.

Fahnestock, M., Scambos, T., Moon, T., Gardner, A., Haran, T., \& Klinger, M., 2016. Rapid large-area mapping of ice flow using Landsat 8. Remote Sensing of Environment, 185, 84-94.

Frezzotti, C. E., Alessandro, C., \& Vittuari, L., 1998. Comparison between glacier ice velocities inferred from GPS and sequential satellite images. Annals of Glaciology, 27(1), pp. 54-60.

Fujii, Y.,1981. Aerophotographic interpretation of surface features and an estimation of ice discharge at the outlet of the Shirase drainage basin, Antarctica.

Gardner, A. S., Moholdt, G., Scambos, T., Fahnstock, M., Ligtenberg, S., van den Broeke, M., \& Nilsson, J., 2018. Increased West Antarctic and unchanged East Antarctic ice discharge over the last 7 years. Cryosphere, 12(2), 521-547.

Goldstein, R. M., Engelhardt, H., Kamb, B., \& Frolich, R. M., 1993. Satellite radar interferometry for monitoring ice sheet motion: application to an Antarctic ice stream. SCIENCE-NEW YORK THEN WASHINGTON-, 262, pp. 1525-1525.
Jezek, K. C., 2002. RADARSAT-1 Antarctic Mapping Project: change-detection and surface velocity campaign. Annals of Glaciology, 34, 263-268.

Kim, K., Jezek, K. C., \& Liu, H. (2007). Orthorectified image mosaic of Antarctica from 1963 Argon satellite photography: image processing and glaciological applications. International Journal of Remote Sensing, 28(23), 5357-5373.

Leprince, S., Ayoub, F., Klinger, Y., \& Avouac, J. P., 2007. Coregistration of optically sensed images and correlation (COSICorr): An operational methodology for ground deformation measurements. In Geoscience and Remote Sensing Symposium, 2007. IGARSS 2007. IEEE International, pp. 1943-1946.

Li, R., Ye, W., Qiao, G., Tong, X., Liu, S., Kong, F., \& Ma, X., 2017a. A New Analytical Method for Estimating Antarctic Ice Flow in the 1960s From Historical Optical Satellite Imagery. IEEE Transactions on Geoscience and Remote Sensing, 55(5), pp. 2771-2785.

Li, R., Ma, X., Cheng, Y., Ye, W., Guo, S., Tang, G., ... \& Qiao, G., 2017b. Ice Velocity Measurement in East Antarctica from 1960s to 1980s Based on Argon and Landsat Imagery. ISPRSInternational Archives of the Photogrammetry, Remote Sensing and Spatial Information Sciences, XLII-2/W7, pp. 1535-1539.

Li, X., Rignot, E., Mouginot, J., \& Scheuchl, B. ,2016. Ice flow dynamics and mass loss of Totten Glacier, East Antarctica, from 1989 to 2015. Geophysical Research Letters, 43(12), 6366-6373.

Li, X., Li, R., Qiao, G., Cheng, Y., Ye, W., Gao, T., ... \& Tong, X., 2018. Compiling Techniques for East Antarctic Ice Velocity Mapping Based on Historical Optical Imagery. ISPRSInternational Archives of the Photogrammetry, Remote Sensing and Spatial Information Sciences, 2625-2628.

Liu, H., Wang, L., Tang, S. J., \& Jezek, K. C., 2012. Robust multi-scale image matching for deriving ice surface velocity field from sequential satellite images. International journal of remote sensing, 33(6), pp. 1799-1822.

Lucchitta, B. K., \& Ferguson, H. M., 1986. Antarctica: measuring glacier velocity from satellite images. Science, 234, pp. 11051109.

Manson, R., Coleman, R., Morgan, P., \& King, M., 2000. Ice velocities of the Lambert Glacier from static GPS observations. Earth, planets and space, 52(11), pp. 1031-1036.

Mouginot, J., Rignot, E., Scheuchl, B., \& Millan, R., 2017. Comprehensive annual ice sheet velocity mapping using Landsat-8, Sentinel-1, and RADARSAT-2 data. Remote Sensing, 9(4), 364.

Oliver, M. A., \& Webster, R. (1990). Kriging: a method of interpolation for geographical information systems. International Journal of Geographical Information System, 4(3), 313-332.

Reddy, B. S., \& Chatterji, B. N., 1996. An FFT-based technique for translation, rotation, and scale-invariant image registration. IEEE transactions on image processing, 5(8), 1266-1271.

Rignot, E., Mouginot, J., \& Scheuchl, B., 2011. Ice flow of the Antarctic ice sheet. Science, 333(6048), 1427-1430. 
Ruffner, K. C. (Ed.)., 1995. Corona: America's first satellite program. History Staff, Center for the Study of Intelligence, Central Intelligence Agency.

Scambos, T. A., Dutkiewicz, M. J., Wilson, J. C., \& Bindschadler, R. A., 1992. Application of image cross-correlation to the measurement of glacier velocity using satellite image data. Remote sensing of environment, 42(3), pp. 177-186.

Shen, Q., Wang, H., Shum, C. K., Jiang, L., Hsu, H. T., \& Dong, J., 2018. Recent high-resolution Antarctic ice velocity maps reveal increased mass loss in Wilkes Land, East Antarctica. Scientific reports, 8(1), 4477.

Swithinbank, C., 1970. Ice movement in the McMurdo Sound area of Antarctica. In International Symposium on Antarctic Glaciological Exploration (pp. 472-487). Hanover, New Hamphire: International Association of the Science of Hydrology.

Urbini, S., Frezzotti, M., Gandolfi, S., Vincent, C., Scarchilli, C., Vittuari, L., \& Fily, M., 2008. Historical behaviour of Dome C and Talos Dome (East Antarctica) as investigated by snow accumulation and ice velocity measurements. Global and planetary change, 60(3), pp. 576-588.

Whillans, I. M., \& Tseng, Y. H., 1995. Automatic tracking of crevasses on satellite images. Cold Regions Science and Technology, 23(2), pp. 201-214.

Ye, W., Qiao, G., Kong, F., Ma, X., Tong, X., \& Li, R., 2017. Improved Geometric Modeling of 1960s KH-5 ARGON Satellite Images for Regional Antarctica Applications. Photogrammetric Engineering \& Remote Sensing, 83(7), pp. 477-491. 